\title{
Rozwój metod oznaczania siarki w paliwach i w komponentach paliw technikami spektrometrii atomowej
}

\begin{abstract}
W artykule opisano obecnie stosowane znormalizowane metody rutynowego oznaczania siarki w paliwach i biokomponentach paliw. Przedstawiono także najnowsze badania dotyczące oznaczania siarki technikami spektrometrii atomowej, zwracając uwagę na dokładność i precyzję oraz ograniczenie niekorzystnych czynników mających wpływ na jakość wyników analitycznych. Wybór technik spektrometrii atomowej podyktowany był możliwością uzyskania niskich granic oznaczalności oraz wyników charakteryzujących się dobrą precyzją. Wydaje się, że techniki te powinny zostać wykorzystane w większym stopniu przy opracowywaniu nowych metod znormalizowanych oznaczania tego pierwiastka.
\end{abstract}

Słowa kluczowe: oznaczanie siarki, paliwa ciekłe, biokomponenty paliw, spektrometria atomowa.

\section{Development of methods for the determination of sulfur in fuels and fuel components by atomic spectrometry techniques}

\begin{abstract}
The article describes the currently used standardized methods for the routine determination of sulphur in fuels and in biocomponents of fuels. It also describes recent research on the determination of sulphur with the use of atomic spectrometry techniques, paying attention to the accuracy and precision of the determinations, and the reduction of adverse factors affecting the quality of the analytical results. The selection of the atomic spectrometry techniques was dictated because of the ability to obtain low detection limits and results characterized by good precision. It seems that these techniques should be used to a greater extent in the development of novel standardized methods for the determination of this element.
\end{abstract}

Key words: determination of sulphur, liquid fuels, fuel biocomponents, atomic spectrometry.

\section{Wprowadzenie}

Siarkę oznacza się we wszystkich paliwach ciekłych stosowanych w pojazdach samochodowych oraz w biokomponentach paliw. Kontrola jakości produktów spalanych w silnikach samochodowych ma zasadnicze znaczenie ze względu na dbałość o ochronę środowiska oraz utrzymanie odpowiednich właściwości eksploatacyjnych paliw. Związki siarki obecne w paliwach samochodowych odpowiadają za emisję tlenków siarki $\mathrm{SO}_{x}$, które negatywnie oddziałują na środowisko naturalne - w szczególności wywołując zanieczyszczenie atmosfery i kwaśne deszcze. Ponadto mogą być przyczyną działania korozyjnego paliw, zatruwać katalizatory stosowane w układach wydechowych pojazdów samochodowych i w konsekwencji zmniejszać efektywność utleniania tlenku węgla, węglowodorów oraz lotnych związków organicznych. Związki siarki mogą również ograniczać działanie dodatków uszlachetniających. Z tego względu dąży się do zmniejszenia zawartości siarki we wszystkich paliwach oraz w biokomponentach paliw. Dla tych produktów w krajach Unii Europejskiej ustalono dopuszczalne stężenie siarki, nie większe niż $10,0 \mathrm{mg} / \mathrm{kg}$, oraz przygotowano znormalizowane metody oznaczania. Do badania zawartości siarki wybrano następujące techniki analityczne: fluorescencję w nadfiolecie (UVF), spektrometrię rentgenowską z dyspersją fali (WDXRF) i energii (EDXRF) oraz optyczną spektrometrię emisyjną z plazmą sprzężoną indukcyjnie (ICP-OES). Obowiązujące obecnie wymagania dotyczące jakości oleju napędowego, benzyny 
silnikowej, estrów metylowych kwasów tłuszczowych oraz etanolu stosowanego jako komponent benzyn silnikowych są wyszczególnione w specyfikacjach norm europejskich, odpowiednio: PN-EN 590 + A1:2017-06 [25], PN-EN 228 + A1:2017-06 [24], PN-EN 14214 + A1:2014-04 [22] oraz PN-EN 15376:2014-11 [23].

Etanol jako komponent benzyn silnikowych jest jedynym z produktów, dla którego do oznaczania siarki wykorzystuje się optyczną spektrometrię emisyjną z plazmą indukcyjnie sprzężoną (PN-EN 15837:2011 [21]). Dodatkowo, w odróżnieniu od pozostałych paliw i biokomponentów, wprowadzono dla tego produktu oznaczanie siarki w postaci siarczanów(VI), stosując metodę chromatografii jonowej [20]. Związki te nie powinny znajdować się w etanolu wykorzystywa- nym jako komponent benzyny silnikowej w stężeniu większym niż 4,0 mg/kg.

W przypadku pozostałych paliw i komponentów, tj. benzyny silnikowej, oleju napędowego oraz FAME, oznaczanie siarki prowadzi się dla każdego z tych produktów tymi samymi metodami opracowanymi na bazie technik: WDXRF (PN-EN ISO 20884), EDXRF (PN-EN ISO 13032) oraz UVF (PN-EN ISO 20846). Tylko w przypadku etanolu wprowadzono inne metody wykorzystujące techniki WDXRF oraz UVF, jednakże różnią się one od wymienionych wcześniej praktycznie tylko wzorcami używanymi na etapie kalibracji metody. Z tego względu opis znormalizowanych metod oznaczania siarki ograniczono do etanolu, dla którego, jak już wspomniano, wprowadzono normę wykorzystującą technikę spektrometrii atomowej ICP-OES.

\section{Oznaczanie siarki w etanolu metodami znormalizowanymi}

Oznaczanie siarki w etanolu zgodnie z wymaganiami normy PN-EN 15376:2014-11 można przeprowadzić jedną z trzech znormalizowanych metod. Najniższa granica stosowalności odpowiada normie wykorzystującej technikę ICP-OES i wynosi 2,0 mg/kg. Metoda opiera się na zastosowaniu plazmy argonowej do wykrywania oraz wyznaczania stężeń pierwiastków. Wysoka temperatura plazmy indukcyjnie sprzężonej, dochodząca nawet do $10000 \mathrm{~K}$, umożliwia powstanie atomów siarki z jej związków wchodzących w skład próbki, a następnie ich wzbudzenie. Oznaczanie siarki techniką ICP-OES według normy PN-EN 15837:2011 polega na bezpośrednim wprowadzeniu próbki etanolu do komory mgielnej, termostatowanej do temperatury $2^{\circ} \mathrm{C}$. Schłodzenie komory mgielnej stosuje się w celu uniknięcia niestabilności plazmy i jej zgaśnięcia. Wzorce do kalibracji metody przygotowuje się na bazie etanolu. Zakres stosowania metody znajduje się w przedziale od 2,0 mg/kg do $15 \mathrm{mg} / \mathrm{kg}$ siarki. Niepewność rozszerzona $U$ obliczona na podstawie odtwarzalności $R$, podanej w metodzie, nie powinna być większa niż 1,2 mg/kg dla stężenia siarki $10 \mathrm{mg} / \mathrm{kg}$.

Normę PN-EN 15486:2009 [19] opracowano z wykorzystaniem techniki fluorescencji w nadfiolecie. Oznaczanie polega na utlenieniu siarki do ditlenku siarki $\mathrm{SO}_{2}$ poprzez spalenie próbki w temperaturze $1000 \div 1100^{\circ} \mathrm{C}$ w mieszaninie gazów składającej się z gazu nośnego argonu lub helu oraz tlenu. $Z$ powstałych produktów spalania usuwa się wodę, sadzę i inne powstające zanieczyszczenia. Promieniowanie niezbędne do wzbudzenia cząsteczek ditlenku siarki wytwarzane jest przez pulsujące źródło światła. Cząsteczki $\mathrm{SO}_{2}$ poddane działaniu promieniowania przechodzą w stan wzbudzony $\mathrm{SO}_{2}{ }^{*}$ [8]. Promieniowanie fluorescencyjne emitowane podczas powrotu cząsteczek ditlenku siarki ze stanu wzbudzonego do stanu podstawowego - o większej długości fali niż promieniowanie wzbudzające - trafia do detektora. Natężenie promieniowania fluorescencyjnego jest małe, z tego względu jako detektor stosuje się fotopowielacz elektronowy. Precyzję metody opisaną w tej normie wyznaczono dla stężeń siarki w zakresie od 5,0 mg/kg do $20 \mathrm{mg} / \mathrm{kg}$. Niepewność rozszerzona $U$, oszacowana na podstawie odtwarzalności podanej w normie dla stężenia $10 \mathrm{mg} / \mathrm{kg}$, nie powinna być większa niż 2,3 mg/kg.

Stężenie siarki w próbce etanolu według PN-EN 15485:2009 [18] wyznacza się na podstawie krzywej wzorcowej przedstawiającej zależność natężenia fluorescencji rentgenowskiej od stężenia analitu. Badaną próbkę umieszcza się w kuwecie pomiarowej i poddaje ekspozycji pierwotnego promieniowania pochodzącego z lampy rentgenowskiej. Mierzone są szybkości zliczania rentgenowskiego promieniowania fluorescencyjnego linii $\mathrm{S}-\mathrm{K}_{\alpha}$ oraz promieniowania tła [9]. Do przygotowania roztworów wzorcowych wykorzystuje się etanol o czystości co najmniej 99\% ( $\mathrm{m} / \mathrm{m})$ i zawartości siarki poniżej 1,0 mg/kg. Zakres stosowania metody PN-EN 15485:2009 obejmuje stężenie siarki w etanolu od 7,0 mg/kg do $20 \mathrm{mg} / \mathrm{kg}$ i charakteryzuje się niepewnością rozszerzoną $U$, oszacowaną na podstawie odtwarzalności $R$, nie większą niż $2,8 \mathrm{mg} / \mathrm{kg}$ dla stężenia $10 \mathrm{mg} / \mathrm{kg}$.

\section{Metody oznaczania siarki technikami spektrometrii atomowej w paliwach ciekłych}

Oznaczanie siarki w śladowych stężeniach wymaga zastosowania metod analitycznych charakteryzujących się dużą czułością. Najczęściej wykorzystywaną techniką do oznaczania śladowych stężeń siarki w przetworach naftowych jest 
fluorescencja w nadfiolecie (UVF). W technice tej siarka zawarta w próbkach przeprowadzana jest w $\mathrm{SO}_{2}$, chociaż można mieć wątpliwości, czy związki nieorganiczne siarki, jak np. siarczany, są, w warunkach oznaczania, ilościowo przekształcane w ditlenek siarki [12]. Duże znaczenie w analizie próbek produktów naftowych ma spektrometria fluorescencji rentgenowskiej, jednakże należy wspomnieć o ograniczeniu wynikającym z efektów matrycowych spowodowanych obecnością związków zawierających tlen. Rozwiązaniem tego problemu może być przeprowadzenie kalibracji grawimetryczną metodą dodatków wzorca. Metoda ta została wykorzystana do oznaczania siarki na poziomie kilku mg/kg w estrach FAME [2]. Zastosowanie jej podyktowane było wystąpieniem błędu systematycznego oznaczania (około 16\%, przy kalibracji metodą serii wzorców) spowodowanego przez związki zawierające tlen. Wykorzystanie metody dodatków wzorca umożliwiło skorygowanie efektów matrycowych. Jednakże metoda ta nie jest zalecana przy dużej liczbie próbek ze względu na czasochłonność etapu ich przygotowania do analizy.

Technika optycznej spektrometrii emisyjnej plazmy indukcyjnie sprzężonej zyskuje coraz większe znaczenie w oznaczaniu siarki w produktach naftowych. Podstawowe metody wykorzystujące techniki plazmy sprzężonej indukcyjnie opierają się na bezpośrednim wprowadzaniu próbek do układu pomiarowego. Jednakże w przypadku próbek organicznych charakteryzujących się niskimi temperaturami wrzenia, tj. poniżej $140^{\circ} \mathrm{C}$, mogą wystąpić problemy ze stabilnością plazmy. W analityce produktów naftowych zasadniczą rolę w osiągnięciu odpowiedniej dokładności pomiarów odgrywa zgodność matrycy wzorców z matrycą próbki. W wielu przypadkach uzyskanie takiej zgodności może okazać się niemożliwe i dlatego należy zastosować metodę wzorca wewnętrznego lub metodę dodatków wzorca czy też połączenie obu tych metod [11].

De Oliveira i współpracownicy [12] przeprowadzili porównanie wyników analiz estrów FAME technikami ICP-OES oraz UVF, wykorzystując do tego celu certyfikowane materiały odniesienia oraz próbki dostępne na rynku paliw. Oznaczanie siarki techniką ICP-OES wykonano według brazylijskiej normy ABNT NBR 15867. Wzorce robocze siarki zostały przygotowane poprzez odpowiednie rozcieńczenie naftą roztworu podstawowego siarki w oleju mineralnym. Otrzymane wyniki przedstawiono w tablicy 1.

Autorzy pracy sprawdzili korelację pomiędzy wynikami otrzymanymi obiema technikami, uzyskując współczynnik korelacji $R$ równy 0,9997, świadczący o silnym powiązaniu pomiędzy oznaczanymi stężeniami. Należy jednak zwrócić uwagę na podane w pracy stwierdzenie o braku wpływu siarki w postaci związków nieorganicznych na wynik uzyskany techniką UVF. W publikacji przyjęto, że siarka wprowadzona do certyfikowane- go materiału odniesienia Specx FAME (5 mg/kg) występuje w postaci siarczanu(VI) amonu, w rzeczywistości jest to siarczek dibutylu, w związku z tym wniosek o braku wpływu siarki nieorganicznej na dokładność wyniku oznaczenia techniką UVF nie jest uzasadniony.

Oprócz metod analizy bezpośredniej do oznaczania siarki technikami ICP-OES wykorzystano tworzenie emulsji. Do jej przygotowania w pracy Santelli i wsp. [14] stosowano surfaktant Triton X-100. Z próbek benzyny, nafty lub oleju napędowego, odczynnika Triton X-100 oraz stężonego kwasu azotowego(V) i wody sporządzano emulsję o składzie odpowiednio 7\% (próbka), 10\%, 5\% i 78\% ( $V / V)$. Autorzy pracy sprawdzili dokładność oznaczeń siarki całkowitej poprzez wykorzystanie certyfikowanych materiałów odniesienia: NIST 2298 (benzyna silnikowa), NIST 2723a (olej napędowy) i NIST 1616b (nafta). Przeprowadzono również badania odzysku, wprowadzając siarkę w odpowiednich stężeniach do próbek benzyny, oleju napędowego i nafty. Uzyskano dobrą zgodność pomiędzy wartościami certyfikowanymi stężeń siarki a oznaczonymi. W próbkach, do których wprowadzono związki siarki, odzysk kształtował się w przedziale $94 \div 103 \%$. W innej pracy [17] podobny sposób tworzenia emulsji zastosowano do estrów metylowych kwasów tłuszczowych FAME. Próbki do analizy przygotowano poprzez zmieszanie $0,5 \mathrm{ml} 20$-proc. $(V / V)$ kwasu azotowego(V) i 0,5 ml odczynnika Triton X-100 z 2 $\div 3$ ml FAME. Całość rozcieńczono n-propanolem do objętości $10 \mathrm{ml}$ i poddano ujednorodnianiu, intensywnie mieszając przez $2 \mathrm{~min}$. Analogiczne postępowanie zastosowano do przygotowania roztworów do wzorcowania oznaczeń, bazując na wykorzystaniu wodnych, nieorganicznych roztworów podstawowych. Autorzy pracy przeprowadzili sumowanie intensywności linii spektralnych siarki z zakresu nadfioletu: $182,034 \mathrm{~nm}, 180,731 \mathrm{~nm}$ i 182,624 nm. W wyniku tej operacji matematycznej uzyskano polepszenie czułości oznaczań.

Oznaczanie pierwiastków śladowych w FAME przeprowadzano również na drodze rozcieńczenia estrów etanolem lub 1-propanolem [5]. Przy czym korzystniejszy do celów analizy

Tablica 1. Wyniki oznaczeń siarki technikami UVF oraz ICP-OES w próbkach certyfikowanych materiałów odniesienia oraz FAME dostępnych na rynku paliw; $C$ - stężenie siarki w $\mathrm{mg} / \mathrm{kg}$, $S D$ - odchylenie standardowe [12]

\begin{tabular}{|l|c|c|}
\hline \multicolumn{1}{|c|}{ Próbka } & $\begin{array}{c}\text { UVF } \\
\mathrm{C} \pm \mathrm{SD} \\
{[\mathrm{mg} / \mathrm{kg}]}\end{array}$ & $\begin{array}{c}\text { ICP-OES } \\
\mathrm{C} \pm \mathrm{SD} \\
{[\mathrm{mg} / \mathrm{kg}]}\end{array}$ \\
\hline NIST 2773 - CRM FAME $7,39 \mathrm{mg} / \mathrm{kg} \mathrm{S}$ & $7,5 \pm 0,3$ & $8,4 \pm 0,2$ \\
\hline Spex CRM FAME $5,0 \mathrm{mg} / \mathrm{kg}$ & $5,2 \pm 0,4$ & $5,0 \pm 0,1$ \\
\hline EP FAME & $37,8 \pm 1,1$ & $40,0 \pm 0,7$ \\
\hline TEP FAME & $<\mathrm{LOD}$ & $<0,8$ \\
\hline Mieszanina EP i TEP & $2,6 \pm 0,2$ & $2,9 \pm 0,1$ \\
\hline
\end{tabular}


okazał się 1-propanol, który wrze w temperaturze $97^{\circ} \mathrm{C}$. Rozcieńczenie próbki alkoholem pociąga za sobą konieczność zastosowania chłodzonej komory mgielnej - dla utrzymania stabilności plazmy. W warunkach schłodzenia jej do temperatury $-5^{\circ} \mathrm{C}$ w znaczący sposób ogranicza się ilość wprowadzanego do plazmy rozpuszczalnika, przez co zwiększa się jej stabilność. Zastosowanie przez autorów pracy rozcieńczenia próbki alkoholem dało możliwość wzorcowania metody z wykorzystaniem wodnego roztworu podstawowego pierwiastków. Do korekcji fizycznych interferencji i płynięcia sygnału zastosowano jako wzorzec wewnętrzny itr, w stężeniu we wzorcach roboczych $1 \mathrm{mg} / \mathrm{L}$. Dla certyfikowanego materiału odniesienia NIST SRM 2773 (FAME na bazie tłuszczów zwierzęcych) o stężeniu siarki 7,36 mg/kg uzyskano wyniki przy rozcieńczeniu etanolem $6,9 \pm 0,5 \mathrm{mg} / \mathrm{kg}$ oraz $7,4 \pm 0,3 \mathrm{mg} / \mathrm{kg}$ w przypadku zastosowania 1-propanolu.

Opracowano również metodę opierającą się na wykorzystaniu spalania wywoływanego promieniowaniem mikrofalowym MIC (ang. microwave-induced combustion) [6]. Spalanie próbki oleju napędowego zachodzi w zamkniętym naczyniu kwarcowym wypełnionym tlenem oraz kwasem azotowy$\mathrm{m}(\mathrm{V})$, pełniącym funkcję roztworu pochłaniającego. Spalanie odbywa się w temperaturze powyżej $1000^{\circ} \mathrm{C}$, w wyniku czego zachodzi całkowita mineralizacja próbki. Dodatkowo podgrzewanie mikrofalowe kwasu, w zamkniętym naczyniu, wywołuje jego refluks, co w konsekwencji prowadzi do polepszenia odzysku analitu. Jako spowalniacz spalania próbki oleju napędowego zastosowano wełnę szklaną, na którą naniesiono olej napędowy (400 mg oleju napędowego na $100 \mathrm{mg}$ wełny szklanej). Oznaczanie siarki w roztworze po procesie spalania wykonano techniką ICP-OES. Sprawdzenie metody przeprowadzono z wykorzystaniem oleju napędowego (CRM NIST SRM 1048a). Autorzy uzyskali dobrą zgodność pomiędzy wartością certyfikowaną a wynikiem oznaczania techniką ICP-OES.

Atomowa spektrometria absorpcyjna nie jest stosowana do bezpośredniego oznaczania siarki. Przyczyny tego ograniczenia są następujące: linie atomowe siarki znajdują się w zakresie nadfioletu próżniowego, tj.: 180,671 nm, 181,671 nm i $182,565 \mathrm{~nm}$, a temperatura panująca $\mathrm{w}$ atomizerach używanych $\mathrm{w}$ atomowej spektrometrii absorpcyjnej jest zbyt mała, aby wytworzyć wolne atomy siarki. W związku z tym powstały pośrednie metody oznaczania siarki wykorzystujące strącanie siarczanów(VI) baru [3] lub ołowiu [4]. Jednakże tego rodzaju postępowanie analityczne wymaga dużej selektywności reakcji wytrącania i jest z reguły pracochłonne. Alternatywą dla metod bazujących na tworzeniu wolnych atomów siarki jako źródła sygnału analitycznego jest wykorzystanie widma cząsteczkowego. Użytecznym urządzeniem do oznaczania siarki okazał się wysokorozdzielczy spektrometr absorpcji atomowej z ciągłym źródłem promieniowania HR CS AAS. W instrumencie tym wykorzystano jako źródło promieniowania ciągłego lampę ksenonową, wypełnioną ksenonem pod ciśnieniem około 17 barów. Lampa ta wytwarza promieniowanie o dużym natężeniu w całym zakresie długości fali od $185 \mathrm{~nm}$ do $900 \mathrm{~nm}$. Spektrometr ten pozwala na uzyskanie bardzo wysokiej rozdzielczości - około 1,5 pm/piksel przy długości fali $200 \mathrm{~nm}$ dzięki zastosowaniu układu podwójnego monochromatora. Do oznaczania siarki techniką płomieniowej HR CS FAAS wykorzystuje się głównie linie cząsteczki CS, której energia dysocjacji $713,4 \mathrm{~kJ} \cdot \mathrm{mol}^{-1}$ jest wystarczająco duża (tzn. $>500 \mathrm{~kJ} \cdot \mathrm{mol}^{-1}$ ), aby zapewnić trwałość cząsteczek w fazie gazowej [13]. Stosuje się bogatą w gaz palny mieszankę zasilającą palnik, która sprzyja tworzeniu cząsteczek CS. Czułe pasmo widmowe CS, najczęściej wybierane do oznaczania siarki w produktach naftowych, znajduje się w okolicy $258 \mathrm{~nm}(257,913 \div 258,198)$. Kowalewska [10] wykorzystała linię 258,056 nm do oznaczania siarki w produktach naftowych techniką HR CS AAS, stosując atomizer płomieniowy i elektrotermiczny. W przypadku oznaczania lotnych związków siarki, takich jak np. $\mathrm{CS}_{2}$ (obecny w lekkich produktach naftowych, np. w benzynie), technika płomieniowa, ze względu na zbyt dużą i zmienną wydajność odparowania, nie powinna być stosowana. Natomiast użycie atomizera elektrotermicznego w przypadku trwałych i lotnych związków siarki może spowodować przeprowadzenie ich w postać par bez rozerwania istniejących wiązań i utworzenia CS.

Siarka posiada cztery stabilne izotopy o nominalnych masach 32, 33, 34 i 36, odpowiednio o abundancji: 94,99\%, $0,75 \%, 4,25 \%$ i $0,01 \%$ [7]. Stosunkowo wysoki pierwszy potencjał jonizacji siarki $(10,357 \mathrm{eV})$ odpowiada za względnie małą wydajność jonizacji w plazmie argonowej. Ponadto masa atomowa siarki jest w zakresie 32,059 $\div 32,076 \mathrm{u}$ (według IUPAC [15]) i w związku z tym nie uzyskuje się dla niej tak dobrej czułości oznaczań techniką spektrometrii mas plazmy indukcyjnie sprzężonej jak dla pierwiastków ciężkich. Dodatkowym czynnikiem wpływającym na oznaczanie siarki są interferencje spektralne. Interferencje te wynikają z ograniczonej rozdzielczości spektrometru mas, za pomocą którego nie jesteśmy w stanie odróżnić jonów oznaczanego pierwiastka od jonów izobarycznych, dwudodatnich czy wieloatomowych, charakteryzujących się tą samą wartością stosunku masy do ładunku $(\mathrm{m} / \mathrm{z})$. W tablicy 2 przedstawiono główne interferencje spektralne dla izotopów siarki.

Interferencje izobaryczne występują tylko dla izotopu siarki o najmniejszej abundancji ${ }^{36} \mathrm{~S}^{+}$, i odpowiadają za nie jony argonu ${ }^{36} \mathrm{Ar}^{+}$. Natomiast w przypadku pozostałych izotopów interferencje pochodzą od jonów wieloatomowych. Największe ograniczenie dla oznaczania siarki z dużą czułością, którą uzyskuje się dla izotopu o największej abundancji, stanowią 
Tablica 2. Interferencje spektralne dla siarki w metodzie spektrometrii mas oraz rozdzielczości, przy których można oddzielić linie analitu od interferenta [7]

\begin{tabular}{|c|c|c|c|}
\hline Analit & $\begin{array}{c}\text { Abundancja } \\
{[\%]}\end{array}$ & Interferencje spektralne & $\begin{array}{c}\text { Rozdzielczość } \\
{[\mathrm{m} / \Delta \mathrm{m}]}\end{array}$ \\
\hline \multirow{3}{*}{${ }^{32} \mathrm{~S}^{+}$} & \multirow{2}{*}{94,99} & ${ }^{16} \mathrm{O}^{16} \mathrm{O}^{+}$ & 1801 \\
& & ${ }^{14} \mathrm{~N}^{18} \mathrm{O}^{+}$ & 1061 \\
& & ${ }^{15} \mathrm{~N}^{16} \mathrm{O}^{1} \mathrm{H}^{+}$ & 1040 \\
& & ${ }^{14} \mathrm{~N}^{16} \mathrm{O}^{1} \mathrm{H}^{+}$ & 700 \\
\hline${ }^{33} \mathrm{~S}^{+}$ & 0,75 & ${ }^{32} \mathrm{~S}^{1} \mathrm{H}^{+}$ & 3907 \\
& & ${ }^{16} \mathrm{O}^{16} \mathrm{O}^{1} \mathrm{H}^{+}$ & 1259 \\
& & ${ }^{14} \mathrm{~N}^{18} \mathrm{O}^{1} \mathrm{H}^{+}$ & 854 \\
& & ${ }^{15} \mathrm{~N}^{18} \mathrm{O}^{+}$ & 1186 \\
\hline${ }^{34} \mathrm{~S}^{+}$ & 4,25 & ${ }^{33} \mathrm{~S}^{1} \mathrm{H}^{+}$ & 2977 \\
& & ${ }^{32} \mathrm{~S}^{1} \mathrm{H}^{+}$ & 1711 \\
& & ${ }^{16} \mathrm{O}^{18} \mathrm{O}^{+}$ & 1297 \\
& & ${ }^{16} \mathrm{O}^{17} \mathrm{O}^{1} \mathrm{H}^{+}$ & 1000 \\
\hline${ }^{36} \mathrm{~S}^{+}$ & 0,01 & ${ }^{16} \mathrm{O}^{16} \mathrm{O}^{1} \mathrm{H}^{+}$ & 904 \\
\hline
\end{tabular}

interferencje pochodzące od dimeru tlenu ${ }^{16} \mathrm{O}^{16} \mathrm{O}^{+}$. Jednym z najprostszych sposobów uniknięcia spektralnych efektów interferencyjnych, kosztem zmniejszenia czułości, jest wykorzystanie linii izotopów siarki charakteryzujących się słabymi interferencjami, np. linii ${ }^{34} \mathrm{~S}^{+}$. Natomiast stosując spektrometr o wysokiej rozdzielczości, tj. HR ICP-MS, można uniknąć praktycz- nie wszystkich interferencji wywołanych jonami wieloatomowymi przy rozdzielczości $4000(\mathrm{~m} / \Delta \mathrm{m})$. Amais i współpracownicy [1] wykorzystali wysokorozdzielczy spektrometr ICP-MS do oznaczania siarki w FAME i oleju napędowym z zastosowaniem metody rozcieńczania izotopowego. Próbki przygotowano do analizy poprzez mineralizację mikrofalową ze stężonym kwasem azotowym(V), wodą oraz stężonym roztworem nadtlenku wodoru. Wzbogacenie izotopowe próbki przeprowadzono, stosując materiał zawierający siarkę, w której ${ }^{34} \mathrm{~S}$ stanowi 99,9999\%. Pomiary przeprowadzono przy średniej rozdzielczości spektrometru równej 4500. Autorzy uzyskali dokładne wyniki dla znakomitej większości próbek - z wyjątkiem materiałów, w których siarka znajdowała się w stężeniu mniejszym niż $1 \mathrm{mg} / \mathrm{kg}$. Jednakże należy podkreślić, że spektrometry wysokorozdzielcze są bardzo drogimi urządzeniami, w związku z czym do eliminacji jonów interferujących opracowano sposoby wykorzystujące znacznie tańsze rozwiązanie - spektrometry o niskiej rozdzielczości wyposażone w komory zderzeniowe i reakcyjne. Tego rodzaju komory znajdują się za palnikiem plazmowym spektrometru ICP-MS i zbudowane są z multipola (kwadrupola, heksapola lub oktopola). W obszarze multipola następuje skupienie jonów, które następnie ulegają rozbiciu lub reakcji w wyniku kontaktu $z$ gazem wprowadzanym do komory. $\mathrm{Z}$ zastosowaniem spektrometru $\mathrm{z}$ komorą zderzeniową/ reakcyjną oznaczano siarkę w FAME w postaci ${ }^{32} \mathrm{~S}^{+}$, wprowadzając do komory reakcyjnej ksenon w celu usunięcia interferencji pochodzących od tlenu [26].

\section{Podsumowanie i wnioski}

W artykule opisano stosowane obecnie znormalizowane oraz wybrane z literatury metody oznaczania siarki w paliwach i biokomponentach paliw. Przedstawiono także najnowsze badania dotyczące oznaczania siarki technikami spektrometrii atomowej, zwracając uwagę na dokładność i precyzję oznaczeń oraz sposoby ograniczania niekorzystnych czynników mających wpływ na jakość wyników analitycznych. Wybór technik spektrometrii atomowej podyktowany był możliwością uzyskania niskich granic oznaczalności oraz wyników charakteryzujących się dobrą precyzją.

W odniesieniu do znormalizowanych metod dotyczących rutynowego oznaczania siarki w paliwach i komponentach pa- liw - tylko jedna z nich wykorzystuje spektrometrię atomową do oznaczania siarki w etanolu stanowiącym komponent benzyny silnikowej. Pozostałe normy opierają się na technikach fluorescencji w nadfiolecie lub fluorescencji rentgenowskiej.

Można wnioskować, że techniki spektrometrii atomowej powinny znaleźć szersze zastosowanie w rutynowym oznaczaniu siarki w oleju napędowym i w FAME. Związane jest to z koniecznością opracowania nowych, znormalizowanych metod oznaczania tego pierwiastka lub rozszerzenia o oznaczanie siarki zakresu już istniejących norm wykorzystujących technikę ICP-OES (np. do oznaczania metali w oleju napędowym).

Prosimy cytować jako: Nafta-Gaz 2018, nr 8, s. 619-624, DOI: 10.18668/NG.2018.08.08

Artykuł przysłany do Redakcji 24.11.2017 r. Zatwierdzony do druku 15.07.2018 r.

Artykuł powstał na podstawie pracy statutowej pt. Badania nad poprawnościa oznaczań siarki w biokomponentach paliw - praca INiG na zlecenie MNiSW; nr zlecenia: 0107/17, nr archiwalny: DK-4100-94/17. 


\section{Literatura}

[1] Amais R.S., Long S.E., Nobrega J.A., Christopher S.J.: Determination of trace sulfur in biodiesel and diesel standard reference materials by isotope dilution sector field inductively coupled plasma mass spectrometry. Anal. Chim. Acta 2014, vol. 806, s. 91-96.

[2] Barker L.R., Kelly W.R., Guthrie W.F.: Determination of sulfur in biodiesel and petroleum diesel by $X-$ ray fluorescence (XRF) using the gravimetric standard addition method - II. Energy \& Fuels 2008, vol. 22, nr 4, s. 2488-2490.

[3] Campbell A.D., Tioh N.H.: The determination of sulphate in fertilizers by atomic absorption spectrometry. Anal. Chim. Acta 1978, vol. 100, s. 451-455.

[4] Campbell A.D., Tioh N.H.: The determination of Sulphur dioxide by atomic absorption spectrometry after precipitation of lead sulphate. Anal. Chim. Acta 1969, vol. 44, nr 1, s. 239-241.

[5] Chaves E.S., de Loos-Vollebregt M.T.C., Curtius A.J., Vanhaecke F.: Determination of trace elements in biodiesel and vegetable oil by inductively coupled plasma optical emission spectrometry following alcohol dilution. Spectrochim. Acta 2011, Part B, vol. 66, nr 9, s. 733-739.

[6] Cruz S.M., Trik P., Dalla Nora F.M., Schmidt L., Wiltsche H., Bizzi C.A., Knapp G., Flores E.M.M.: Feasibility of sulfur determination in diesel oil by inductively coupled plasma optical emission spectrometry after microwave-induced combustion using flame retardant. Fuel 2015, vol. 160, s. 108-113.

[7] Giner Nartinez-Sierra J., Galilea San Blas O., Marchante Gayon J.M., Garcia Alonso J.I.: Sulphur analysis by inductively coupled plasma - mass spectrometry: A review determination in petroleum products. Spectrochim. Acta 2015, Part B, vol. 108, s. $35-52$.

[8] Jędrychowska S.: Oznaczanie zawartości siarki w bioetanolu stużacym jako komponent benzyn silnikowych. Nafta-Gaz 2010, nr 12, s. 1176-1182.

[9] Jędrychowska S., Wieczorek A.: Analiza wielopierwiastkowa środków smarowych z wykorzystaniem techniki spektrometrii fluorescencji rentgenowskiej z dyspersja fali. Nafta-Gaz 2013, nr 6, s. 476-485.

[10] Kowalewska Z.: Feasibility of high-resolution continuum source atomic absorption spectrometry in flame and furnace for sulphur determination in petroleum products. Spectrochim. Acta 2011, Part B, vol. 66, nr 7, s. 546-556.

[11] Kozak M.: Zastosowanie metody ISM-SAM do oznaczania pierwiastków śladowych w oleju napędowym. Nafta-Gaz 2017, nr 9, s. 691-697, DOI: 10.18668/NG.2017.09.09.

[12] de Oliveira Filho W.P., Borges D.L.G., Saint Pierre D.T., Dupim M., Vale F., Marques B., Medeiros F.R.: Assessment of the equivalence and correlation between total sulfur determination methods in biodiesel: An use of isotope dilution inductively coupled plasma mass spectrometry. Fuel 2017, vol. 202, s. 227-232.

[13] Ozbek N., Baysal A.: Determination of sulphur by high-resolution continuum source atomic absorption spectrometry: Review of studies over the last 10 years. TrAC Trends Anal. Chem. 2017, vol. 88, s. 62-76.
[14] Santelli R.E., Oliveira E.P., de Carvalho M.B., Bezerra M.A., Freire A.S.: Total sulfur determination in gasoline, kerosene and diesel fuel using inductively coupled plasma optical emission spectrometry after direct sample introduction as detergent emulsions. Spectrochim. Acta 2008, Part B, vol. 63, nr 7, s. 800-804.

[15] Wieser M.E., Coplen T.B.: Atomic weight of the elements 2009 (IUPAC technical report). Pure Appl. Chem. 2011, vol. 83, nr 2, s. 359-396.

[16] Woods G.D., Fryer F.I.: Direct elemental analysis of biodiesel by inductively coupled plasma - mass spectrometry. Anal. Bioanal. Chem. 2007, vol. 389, nr 3, s. 753-761.

[17] Young C.G., Amais R.S., Schiavo D., Garcia E.E., Nobrega J.A., Jones B.T.: Determination of sulfur in biodiesel microemulsions using the summation of the intensities of multiple emission lines. Talanta 2011, vol. 84, nr 3, s. 995-999.

\section{Akty prawne i normatywne}

[18] PN-EN 15485:2009 Etanol jako komponent benzyny silnikowej-Oznaczanie zawartości siarki - Rentgenowska spektrometria fluorescencyjna $z$ dyspersja fali.

[19] PN-EN 15486:2009 Etanol jako komponent benzyny silnikowej - Oznaczanie zawartości siarki - Metoda fluorescencji $w$ nadfiolecie.

[20] PN-EN 15492:2012 Etanol jako komponent benzyny silnikowej-Oznaczanie zawartości chlorku nieorganicznego i siarczanu - Metoda chromatografii jonowej.

[21] PN-EN 15837:2011 Etanol jako komponent benzyn silnikowych - Oznaczanie zawartości fosforu, miedzi i siarki - Metoda bezpośrednia z zastosowaniem optycznej spektrometrii emisyjnej indukcyjnie sprzężonej plazmy (ICP OES).

[22] PNEN 14214 + A1:2014-04 Ciekte przetwory naftowe - Estry metylowe kwasów tluszczowych (FAME) do użytku w silnikach samochodowych o zapłonie samoczynnym (Diesla) $i$ zastosowań grzewczych - Wymagania i metody badań.

[23] PN-EN 15376:2014-11 Paliwa do pojazdów samochodowychEtanol jako komponent benzyny silnikowej - Wymagania i metody badań.

[24] PN-EN 228 + A1:2017-06 Paliwa do pojazdów samochodowych - Benzyna bezolowiowa - Wymagania i metody badań.

[25] PN-EN 590 + A1:2017-06 Paliwa do pojazdów samochodowych - Oleje napędowe - Wymagania i metody badań.

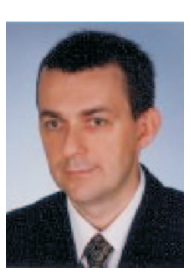

Dr Marek KOZAK

Adiunkt w Zakładzie Analiz Naftowych. Instytut Nafty i Gazu - Państwowy Instytut Badawczy ul. Lubicz 25A

31-503 Kraków

E-mail: marek.kozak@inig.pl 